\title{
EVALUATING THE DROUGHT STRESS TOLERANCE EFFICIENCY OF WHEAT (TRITICUM AESTIVUM L.) CULTIVARS
}

\author{
M.A. Sammar Raza ${ }^{1}$, M.F. Saleem ${ }^{2}$, I.H. Khan ${ }^{3}$, M. Jamil ${ }^{1}$, M. Ijaz ${ }^{1}$, M.A. Khan ${ }^{1}$, Researchers \\ ${ }^{1}$ University College of Agriculture \& Environmental Sciences \\ The Islamia University of Bahawalpur, Pakistan \\ ${ }^{2}$ Department of Agronomy, University of Agriculture, \\ Faisalabad, Pakistan \\ ${ }^{3}$ Department of Agronomy, College of Agriculture, University of Agriculture, \\ Faisalabad, Pakistan \\ E-mail: mueen_1981@yahoo.com, Phone: +92629255531
}

Received December 19, 2012

\begin{abstract}
The study was conducted at the Nuclear Institute for Agriculture and Biology (NIAB), Faisalabad, Pakistan to evaluate the drought stress tolerance efficiency of wheat cultivars. Eight wheat (Triticum aestivum L.) genotypes namely (Pasban-90, Inqalab-91, Auqab-2000, AS-2002, Sahar-2006, Shafaq2006, Lasani-2008, and FSD-2008) were used for screening in laboratory. Three techniques were used for the screening. These techniques are (I) seed germination at -0.6 MPa external water potential (PEG-6000), (2) seedling growth after 14 days at -0.6 MPa (PEG-6000), and (3) plant water relations of seven-week-old pot-grown plants. Significantly highest germination stress tolerance index, root length stress tolerance index and the water content was recorded in Lasani-2008 and lowest was recorded in Auqab-2000. Dry matter percentage was recorded significantly highest in pasban-90 while the lowest dry matter percentage was observed in auqab-2000. FSD-2008 gained maximum plant height and was recorded minimum in Inqilab-91. Relative saturation deficit was significantly highest in Auqab-2000 while the significantly lowest relative saturation deficit was recorded in case of Lasani-2008. It was concluded from the results that Lasani-2008 performed better under drought and Auqab-2000 was recorded most drought sensitive variety.
\end{abstract}

\section{KEY WORDS}

Drought stress; Wheat; Relative water content; Stress tolerance index.

Water, the most important component of life, is rapidly becoming a critically short commodity for humans and their crops. Shortage of water limits plant growth and crop productivity in arid regions more than any other single environmental factor (Boyer, 1982). Wheat (Triticum aestivum L.) is a staple food of about one third of the world's population. It is one of the most important cereals which provide more calories in the form of starch and proteins; besides vitamins I and diet than any other food crop (Govt. of Pakistan, 2004). Water stress reduces crop yield regardless of the growth stage at which it occurs in wheat. Arid and semi arid environment besides other factors may induce water stress during crop growth and development, resulting a reduction in crop yield (Ashraf et al., 1995). In spite water stress is recognized as an important factor that affects wheat growth and yield (Ashraf and Naqvi, 1995; Ashraf, 1998), differences among cultivars were found in response to soil moisture restrictions (Rascio et al., 1992; Iqbal et al., 1999).

Turgor maintenance plays an important role in drought tolerance of plants which may be due to its involvement in stomatal regulation and hence photosynthesis (Ludlow et al., 1985). Water is essential at every stage of plant growth from seed germination to plant maturation. Water stress reduces crop yield regardless of the growth stage at which it occurs the adverse effect of water stress on crop yield may be more pronounced at some particular growth stage (El-Far and Allan, 1995) depending upon the nature of crop species and even genotypes within the species.

To cope with drought stress to have handsome crop growth and yield, breeding for drought 
tolerance can best be accomplished by selecting for grain yield under field conditions (Richards, 1978), but such procedures require full season field data. It is not always an efficient approach, especially in mesic locations. An alternative may be to screen material under laboratory or greenhouse conditions using seedlings as test material. Evidence has been presented that alfalfa (Medicago sativa L.) accessions that emerge at -0.65 $\mathrm{MPa}$ and soybean at $-0.60 \mathrm{MPa}$ external osmotic pressure show better field emergence and survival under drought than those accessions that do not emerge under laboratory conditions (Johnson and Rumbaugh, 1981). Several physiological characteristics have been reported as being reliable indicators for the selection of germplasm possessing drought tolerance. These characteristics include seed germination and seedling growth in nutrient solutions with low osmotic potential (Ashraf et at, 1992; Blum, 1980; Richards, 1978), the degree of electrolyte leakage (cell membrane stability, CMS) from drought-damaged leaf cells and the water relations of plants (Dedio, 1975; Ashraf et al., 1992).

Screening of different crop plants to abiotic stresses is used to find out most resistant variety (Zafar-ul-Hye et al., 2007). While screening the wheat cultivars for most drought sensitive and most drought tolerant genotype it was considered that the success of these approaches under green house and lab conditions depends on their same behavior under field condition also.

\section{MATERIALS AND METHODS}

The experiment was conducted to screen the available wheat germplasm (Inqalab 91, Lasani 2008, FSD 2008, Sahar 2006, Shafaq 2006, AS 2002, Auqab 2000) for drought tolerance. The seeds of all cultivars were obtained from the Wheat Research Institute, (Ayub Agricultural Research Institute), Faisalabad, Pakistan.

The screening experiment (to determine the most drought resistant and most drought sensitive wheat germplasm) was conducted in a growth chamber, Stress Physiology Lab; Nuclear Institute for Agriculture and Biology (NIAB), Faisalabad, Pakistan. The water stress treatments $(0,-$ $0.6 \mathrm{Mpa})$ were created by Polyethylene glycol (PEG-6000). PEG-6000 (0 and 120 g) was dissolved in $1 \mathrm{~L}$ of half strength Hoagland's nutrient solution separately to create water stress treatments of control and -0.6 Mpa, respectively. The seeds were surface sterilized with $10 \%$ sodium hypochlorite solution for five minutes and washed three times with distilled water. Ten seeds were sown in each Petri dish containing filter papers.

The $5 \mathrm{ml}$ of water (control) and $5 \mathrm{ml}$ solution of PEG were added separately in these Petri plates. The experiment was laid out in a completely randomized design with three replicates for each experimental unit. Five $\mathrm{ml}$ of appropriate treatment solution was applied daily in each Petri dish after washing out the previous solution. Number of seeds germinated was counted daily and data were recorded for 14 days. A seed was considered germinated when both plumule and radicle had emerged to $5 \mathrm{~mm}$. Total germination was expressed as percent of that in the control treatment for each line and then data were analyzed statistically. Rate of germination was determined on the basis of days to $50 \%$ germination calculated from the untransformed data. Shoot length and root length, fresh and dry weights/seedling were recorded after 14 days of the start of the experiment.

$$
\text { PI: nd2 (1.00) + nd4 (0.75) + nd6 (0.50) + nd8 (0.25) }
$$

Promptness index is the percentage of seed which germinate at $2^{\text {nd }}, 4^{\text {th }}, 6^{\text {th }}$ and $8^{\text {th }}$ day of observation as indicated by $\mathrm{nd}_{2}, \mathrm{nd}_{4}, \mathrm{nd}_{6}$ and $\mathrm{nd}_{8}$. Percentage of germination stress tolerance index is determined as below:

$$
\begin{gathered}
\text { G.S.I. }(\%)=\frac{\text { Promptness index of stressed seeds }}{\text { Promptness index of control seeds }} \times 100 \\
\text { PHSI (\%) }=\frac{\text { Plant height of stressed plants }}{\text { Plant height of control plant }} \times 100
\end{gathered}
$$

After 14 days seedlings were harvested and their shoot and root length (named as shoot length stress tolerance index and root length stress tolerance index) were recorded.

$$
\begin{aligned}
& \text { RLSI }(\%)=\frac{\text { Root length of stressed plants }}{\text { Root length of control plants }} 100 \\
& \text { SLSI }(\%)=\frac{\text { Shoot length of stressed plants }}{\text { Shoot length of control plants }} 100
\end{aligned}
$$

After drying the plant in oven at $70^{\circ} \mathrm{C}$ for 24 hours, the dry matter stress tolerance index was recorded as follows:

$$
\text { DMSI }(\%)=\frac{\text { Dry matter of stressed plant }}{\text { Dry matter of control plant }} \times 100
$$

Water was withheld for 7 day after the 6 weeks of the germination. In the morning the $2^{\text {nd }}$ fully expanded leaves were taken from each variety and then weighed immediately. Then at room 
temperature they were kept for one night in test tube containing $10 \mathrm{ml}$ of distilled water. The water was removed from the leaves surfaces and leaves were weighed again to obtain turgid weight (saturated weight). Their dry weight was determined after placing leaves in oven at $70^{\circ} \mathrm{C}$ for 24 hours. Relative saturation deficit was determined as follows:

$$
\operatorname{RSD}(\%)=\frac{\text { Saturated weight }- \text { Fresh weight }}{\text { Saturated weight }} \times 100
$$

\section{RESULTS}

Eight wheat genotypes namely (Pasban-90, Inqalab-91, Auqab-2000, AS-2002, Sahar-2006, Shafaq-2006, Lasani-2008, FSD-2008) were chosen for this study to compare the performance of their growth under normal and stress condition in laboratory during 2008.

The data analyzed (Figure 1) indicated the significant variation among genotypes. Significantly highest germination stress tolerance index was recorded in Lasani-2008 (97\%), followed by AS-2002 (94\%), which was at par with FSD-2008 (93\%) and Pasban-90 (93\%). The lowest germination percentage was recorded in Auqab-2000.

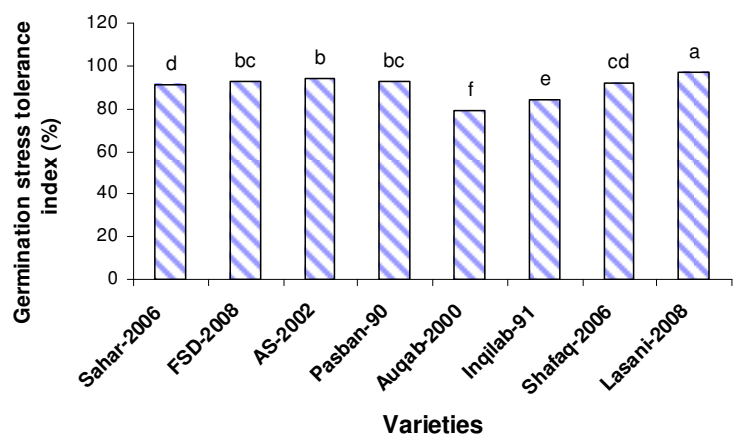

Figure 1 - Germination stress tolerance index (\%) of wheat cultivars after 14 days of growth at 0 and $-0.06 \mathrm{MPa}$ external water potential

Dry matter stress tolerance index of different wheat cultivars (Figure 2) differed significantly. The significantly highest dry matter percentage was recorded in pasban-90 (90\%) while the significantly lowest dry matter percentage was observed in auqab-2000 (61 \%).

Plant height stress tolerance index showed a different pattern for different wheat cultivars. FSD-2008 gained maximum plant height followed by Sahar-2006, Lasani-2008, Pasban-90, AS-2002, Auqab-2000, Shafaq-2006 and Inqilab-91 and all these differ significantly from each other (Figure
3). Plant height was reduced significantly by water deficit.

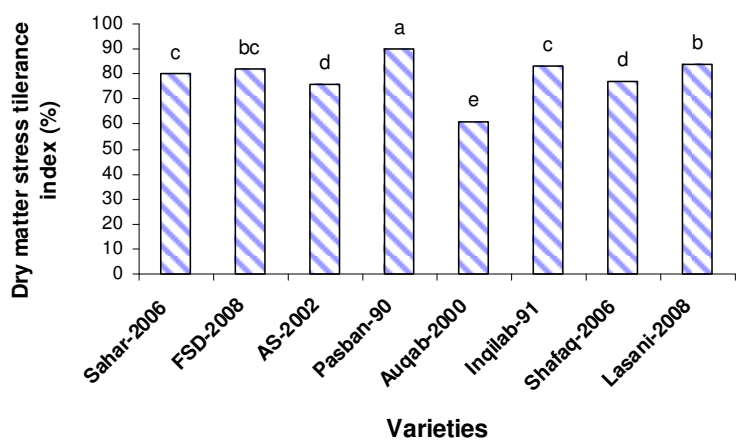

Figure 2 - Dry matter stress tolerance index (\%) of wheat cultivars after 14 days of growth at 0 and $-0.06 \mathrm{MPa}$ external water potential

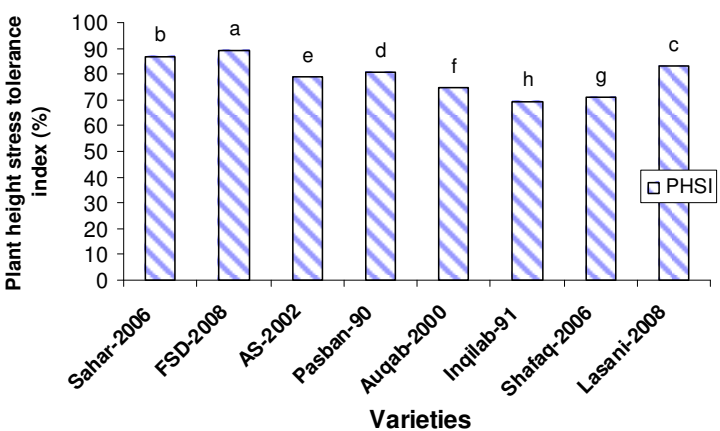

Figure 3 - Plant height stress tolerance index (\%) of wheat cultivars after 14 days of growth at 0 and $-0.06 \mathrm{MPa}$ external water potential

While comparing the growth performance of wheat cultivars under drought it was observed that maximum root length stress tolerance index (99\%) was attained by Lasani-2008 followed by Inqilab91, AS-2002, Pasban-90, Sahar-2006, FSD-2008, Shafaq-2006 and Auqab-2000 and all these varieties differed significantly from each other. Root length was statistically restrained by drought stress (Figure 4).

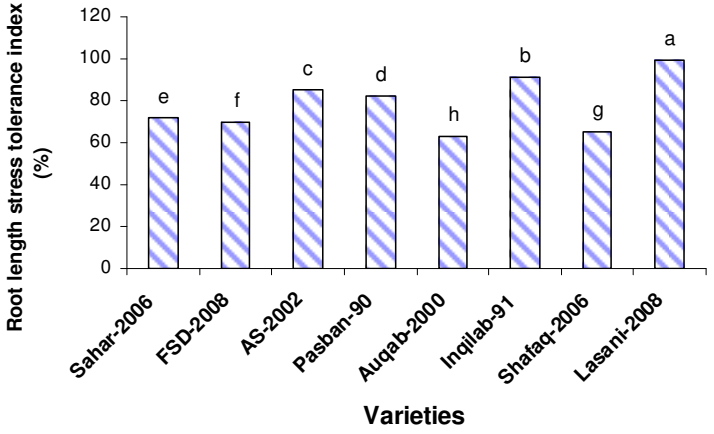

Figure 4 - Root length stress tolerance index (\%) of wheat cultivars after 14 days of growth at 0 and $-0.06 \mathrm{MPa}$ external water potential 
The relative saturation deficit was significantly highest in Auqab-2000 (37\%), followed by Pasban-90 (28\%) while the significantly lowest relative saturation deficit was recorded in case of Lasani-2008 (Figure 5). The differences between FSD-2008 and Sehar-2006 were non-significant; shafaq-2006 and AS-2002 also showed nonsignificant differences with respect to relative saturation deficit (Figure 5).

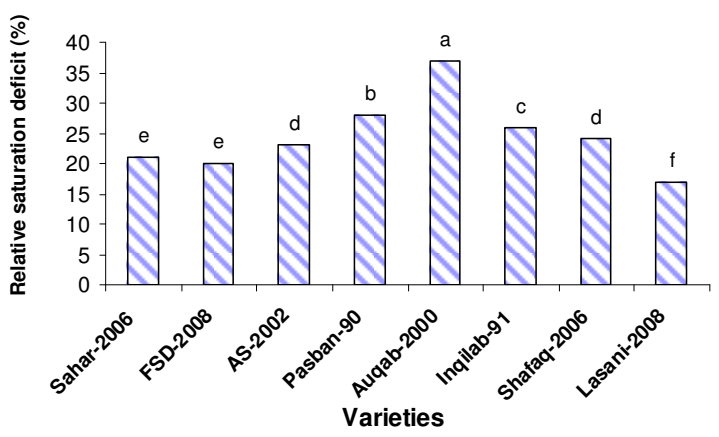

Figure 5 - Relative saturation deficit (\%) of wheat cultivars after 07 days of growth at 0 and $-0.06 \mathrm{MPa}$ external water potential

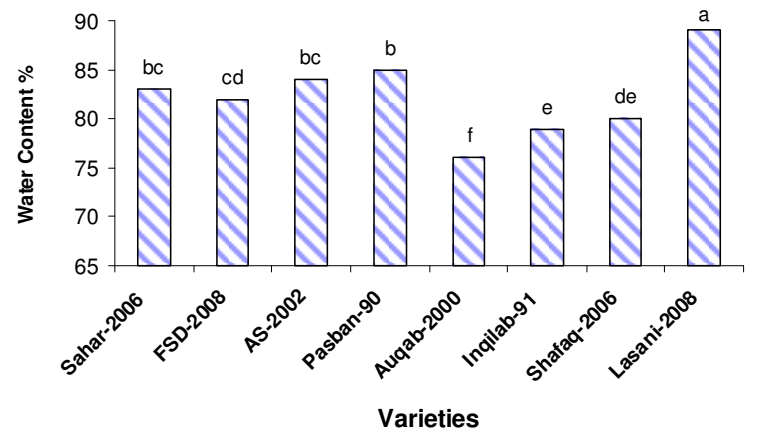

Figure 6 - Water contents (\%) of wheat cultivars after 07 days of growth at 0 and $-0.06 \mathrm{MPa}$ external water potential

The water content was significantly maximum in Lasani-2008 (89\%) followed by Pasban90 which was at par with AS-2002 and Sehar2006.The significantly lowest water content was recorded in case of Auqab-2000 (Figure 6).

\section{DISCUSSION}

Guttieri et al. (2001) reported two different water deficit regimes to screen out sixteen wheat varieties to find out the impact of moisture deficit on wheat growth and yield. Blum et a1. (1980) and Ashraf et al. (1992) investigated that solutions containing polyethylene glycol (PEG) for screening of the wheat seedlings can be used for resistance to drought. Present studies show genotypic variation in germination, plant height, plant dry matter, seedling growth, relative saturation deficit and water contents grown under 0 and $-0.06 \mathrm{Mpa}$. However, not all these parameters proved to be equally effective for screening wheat varieties for their tolerance to stress. It was claimed by Fernandez (1992) that selection based on STI (stress tolerance index) would help to evaluate the higher stress tolerance genotypes with good yield potential. Bouslama and Schapaugh (1984) reported same findings in soybean. Ashraf et al. (1992) concluded that under moisture deficit, germination is not the standard for predicting plant's drought tolerance. However there are other reports (Richards, 1978) indicating germination as a useful criterion in screening for water stress tolerance. Several factors disproved seed quality such as the age of the seed, abiotic factors during plant life, growth and development, harvest and post harvest conditions etc. The response of genotypes may be different to different factors, which could be reflected in their respective seed performances. Thus, for identifying healthy and vigorous seed lots capable of establishing appropriate populations under deficit soil moisture conditions or under abiotic stress (Ibrahim et al., 2007), the germination test of seed may be useful, but these genetic differences may not be related to subsequent growth of seedling and seed yield.

The productivity of genetically different varieties and their consistency is determined by seedling growth plus the correlation of other parameters like dry matter accumulation, plant height and root length. Brukner and Frohberg (1987) reported DSI (dry matter stress tolerance index) as a parameter for measuring genotypic yield potential under drought stress conditions. However, Clarke et al. (1992) reported that DSI did not differentiate yield potential among genotypes. DSI actually a best tool for measuring the yield stability of genotypes based on reducing the yield loss of genotypes under stressed conditions compared to non stressed conditions (Clarke et al., 1982).

Water is widely recognized as important factor for the maintenance of internal water balance required for plant growth, development and/or survival. There is variable number of primary and secondary factors which affect the plants under drought stress (Boyer, 1996). A most common damaging effect of low moisture level or low water potential is the decline in fresh biomass and dry matter production in wheat (Peschke et al., 1997; Ashraf et al., 1998) and rice (Manabendra and Baruah, 1998). This decrease was because of reduced 
photosynthates production under water deficit conditions (Tezara et al., 1999; Anjum et al., 2003; Wahid and Rasul, 2005). Similar findings were resulted by Ashraf and Yasmin (1995) in grasses and by Abrechit and Carberry (1993) in maize. Many workers (Levitt, 1972; Dedio, 1975; Ashraf et at., 1994) have reported that drought tolerant varieties have a smaller water deficit (relative saturation deficit) per unit decrease in water potential of leaf than drought sensitive plants. Siddique et al. (2004) concluded a reduction in RWC of the leaf and leaf water potential, which had significant effect on photosynthesis under deficit moisture conditions. These results are similar with the findings of (Zhu, 2002; Wahid and Close, 2007). Relative water contents (RWC) significantly reduced by creating water stress. Erickson et al. (1991) reported that RWC of leaf indicate the internal water balance of plant tissue and changes in tissue water content change the tissue dry weight continually. The investigations of Dedio (1975), Clarke and McCaig (1982), Ashraf et al. (1994) in screening the excised leaf internal water capabilities,
RSD (relative saturation deficit) or relative water contents of wheat varieties under drought stress conditions indicated that wheat varieties with lower RSD or higher RWC are more droughtresistant. The similar results were also obtained by Carter and Patterson (1985) in soybean. Present study on wheat varieties confirmed the above findings.

\section{CONCLUSION}

Lasani-2008 was selected most drought resistant variety and Auqab-2000 was selected most drought sensitive variety depending upon stress tolerance indices, relative saturation deficit and water contents.

\section{ACKNOWLEDGEMENT}

Lot of thanks to Higher Education Commission, Pakistan for compensating research expenses.

\section{REFERENCES}

Abrechit, D.G. and P.S. Carberry. 1993. The influence of water deficit prior to tassel initiation in maize growth, development and yield. Field Crop Research 31: 55-69.

Anjum, F., M. Yaseen, E. Rasul, A. Wahid and S. Anjum. 2003. Water stress in barley. I. Effect on chemical composition and chlorophyll contents. Pakistan Journal of Agriccultural Sciences 40: 45-9.

Ashraf, M. and N. Yasmin. 1995. Responses of four arid zone grass species from varying habitat to drought stress. Biology of Plant 37: 567-575.

Ashraf, M. Y. and S.S.M. Naqvi. 1995. Studies on water uptake, germination and seedling growth of wheat genotypes under PEG6000 induce water stress. Pakistan Journal of Scientific and Industrial Research 38: 103-133.

Ashraf, M.Y. 1998. Yield and yield components response of wheat (Tritcium aestivum L.) genotypes grown under different soil water deficit conditions. Acta Agronomica Hungarica 46: 45-51.

Ashraf, M.Y., A.R. Azmi, A.H. Khan and S.S.M. Naqvi. 1994. Water relations in different wheat (Triticum aestivum L.) genotypes under soil water deficits. Acta Physiologiae Plantarum 16: 231-240.
Ashraf. M.Y., A.H. Khan and A.R. Azmi. 1992. Cell membrane stability and its relation with some physiological processes in wheat. Acta Agronomica Hungarica 41: 183-191.

Blum. A., B. Sinmena and O. Ziv. 1980. An evaluation of seed and seedling drought tolerance screening tests in wheat. Euphytica 29: 727-736.

Bouslama, M. and W.T. Schapaugh Jr. 1984. Stress tolerance in soybeans. I. Evaluation of three Screening techniques for heat and drought tolerance. Crop Science 24: 933937.

Boyer, J.S. 1982. Plant productivity and environment. Science 218: 443-448.

Boyer, J.S. 1996. Advances in drought tolerances in plants. Advances in Agronomy 56: $187-218$.

Bruckner, P.L. and R.C. Frohberg. 1987. Stress tolerance and adaptation in spring wheat. Crop Science 27: 31-36.

Carter. J.S.Jr. and R.P. Patterson. 1985. Use of relative water content as a selection tool for drought tolerance in soybean. In: Agronomy Abstracts p.7. ASA. Madison. WI.

Clarke, J.M., R.M. Depaw and T.F. TounleySmith. 1992. Evaluation of methods for 
quantification of drought tolerance in wheat. Crop Science 32: 723-728.

Clarke. J.M. and T.N. McCaig. 1982. Evaluation of techniques for screening for drought resistance in wheat. Crop Science 22: 503-506.

Dedio. 1975. Water relations in wheat leaves as screening test for drought resistance. Canadian Journal of Plant Sciences 55: 369-378.

El-Far, I.A. and A.Y. Allan. 1995. Responses of some wheat cultivars to sowing methods and drought at different stages of growth. Assuit Journal of Agricultural Sciences 26: 267-277.

Erickson, I.J., D.L. Ketring and J.F. Stone. 1991. Response of internal tissue water balance of peanut to soil water. Journal of Agronomy 72: 73-80.

Fernandez, G.C.J. 1992. Effective selection criteria for assessing plant stress tolerance. In: Proceedings of on the Symposium Taiwan, August 13-18, 25: 257-270.

Government of Pakistan. 2004. "Economic Survey of Pakistan", Finance Division, Economic Wing, Islamabad, Pakistan.

Guttieri, M.J., J.C. Stark, K.M. O'Brien and E. Souza. 2001. Relative sensitivity of spring wheat grain yield and quality arameters to moisture deficit. Crop Science 41: 327335.

Ibrahim, M., J. Akhtar, M. Younis, M. A. Riaz, M. Anwarul-Haq and M. Tahir. 2007. Selection of cotton (Gossypium hirsutum L.) genotypes against $\mathrm{NaCl}$ stress. Soil and Environment 26(1): 59-63.

Iqbal, M., K. Ahmad, M. Sadiq and M.Y. Ashraf. 1999. Yield and yield components of durum wheat as influenced by water stress at various growth stages. Pakistan Journal of Biological Sciences 2: 11-14.

Johnson, D.A. and M.D. Rambaugh. 1981. Nodulation and acetylene reduction by certain rangeland legume species under field condition. Journal of Range Management 34: 178-181.

Levitt. J. 1972. Response of plants to stresses. Academic Press. New York and London. p.697.

Ludlow, M.M., M.J. Fisher and J.R. Wilson. 1985. Stomatal adjustment to water deficits in three tropical grasses and a tropical legume in controlled conditions and in the field. Journal of Plant Physiology 12: 131149.

Manabendra, D.K. and K. Baruah. 1998. Studies on physiological traits of rice (Oryza sativa L.) cultivars under moisture stress situations. Industrial Journal Ecology 25: 192-196.

Peschke, G., C. Seidler and Yogal. 1997. Effect of drought during the growing season on Agricultural (Triticum aestivum L.) and forest plant canopy (Piceae abies L.). In: Proc. 14tInt. Cong. Biomet., 2(2): Solvenia.

Rascio, A., C. Platani., N. DiFonza and G. Wittemer. 1992. Bound water in durum wheat under drought stress. Plant Physiology 98: 908-912.

Richards, R.A. 1978. Variation between and within species of rapeseed (Brassica campestris and B.napus) in response to drought stress. III. Physiological and physicochemical characters. Australian Journal of Agricultural Research 29: 491-501.

Siddique, M.R.B., A. Hamid and M.S. Islam. 2004. Drought stress effects on water relations of wheat. Botanical Bulletin of Academia Sinica 41:35-39.

Tezara, W., V.J. Mitchell, S.D. Driscoll and D.W. Lawlor. 1999. Water stress inhibits plant photosynthesis by decreasing coupling factor and ATP. Nature 401: 914-917.

Wahid, A. and E. Rasul. 2005. Photosynthesis in leaf, stem, flower and fruit In: Pessarakli M. (Ed). Hand book of Photosynthesis, 2nd Ed., CRC Press, Florida, pp: 479497.

Wahid, A. and T.J. Close. 2007. Expression of dehydrins under heat stress and their relationship with water relations of sugarcane leaves. Biologia Plantarum 51: 104-109.

Zafar-ul-Hye, M., Z.A. Zahir, S.M. Shahzad, U. Irshad and M. Arshad. 2007. Isolation and screening of rhizobia for improving growth and nodulation of lentil (Lens culinaris Medic) seedlings under axenic conditions. Soil and Environment 26(1): 81-91, 2007.

Zhu, J.K. 2002. Salt and drought stress signal transduction in plants. Annual Review of Plant Physiology and Plant Molecular Biology 53: 247-273. 